\title{
An Integrated System Design for Telecom Operators' Investment Management
}

\author{
Ruohong Peng \\ School of Economics and Management, Beijing University of Posts \& Telecommunication, \\ Beijing 100876, China pengrh@263.net
}

\begin{abstract}
With the development of elaborate management, company's MIS become more complex and integrated. As an investment decision making system, it is not a simple financial problem. It should consider not only the company's financial index, but also its internal business process, which always links with the technical part of the company's operation. As an implementation example, this paper focuses on China's mobile operators' investment management system, set up a three-layer system model that's based on the critical path, guided by performance appraisal, impenetrate mobile operator's business process, and aimed at the final profitability. The system integrated functions of controlling, tracing, and decision. It is designed as a dynamic, a timely, and a vigilant one which can keep mobile operators' investment decision right according to their real operating condition.
\end{abstract}

Keywords: MIS, Investment decision, Business process, Mobile operator, KPI, Interrogation

\section{INTRODUCTION}

China's telecommunication has developed rapidly during the past several years. With the continually growth of customer quantity, the network capacity has been expanded every year. Mobile operators have spent huge money in their infrastructure building work. But unfortunately, we saw their profit going down (china mobile's annual report in web ${ }^{[5]}$ ). The marginal profitability of investment has become lower and lower. Its saying that we can't make investment decision only according to the customer increasing, as the investment decision and management does not just relate to the market needs and network capacity, more importantly it should be decided by profitability ${ }^{[1]}$. Nowadays the development of China's telecom market has already entered a smoothly increasing stage, profit margin of investment became smaller and smaller. In this condition, mobile operators need to change their investment criterion from "matching market needs" to "improving capital efficiency". It means that a more comprehensive investment analysis system should build up and including more business process into the decision making. A "profit oriented" investment management system needs to be set up to make their investment decision more reasonable and reliable.

Please use the following format when citing this chapter:

Peng, R., 2007, in IFIP International Federation for Information Processing, Volume 255, Research and Practical Issues of Enterprise Information Systems II Volume 2, eds. L. Xu, Tjoa A., Chaudhry S. (Boston: Springer), pp. 1289-1294. 


\section{ORGANIZATION LOGIC AND STRUCTURE OF THE INVESTMENT MANAGEMENT SYSTEM}

\subsection{The Mechanism of This Information System Design}

As a general conception, a company's value can be increased only by projects with positive NPV, and tracing the whole business approaches, disclose the initial relationship between processes is very important and necessary for managers to grasp the key elements that turning the investment into profit ${ }^{[4]}$. Additionally, the efficiency of investment management should also show its timely and foreseeing characters. So, this system is set up on three basic mechanisms.

1. Base on the internal operation charactors(rules) of a company

All companies have their distinctive producing and operating processes showing their internal business characters. These internal operating characters directly link with some key factors relative to profit (like operation revenue, number of customer, service price, business scale, and investment). So tracing the whole process and digging out the internal disciplines and characters are the basic work and also the theoretical under prop for establishing this management and decision-making system.

2. Insist on a "profit oriented" investment management principle

To aim at company's final profitability, we choose KPI as the criterion to judge company's operating status and give precaution timely. This system is considered to combine company's investment management closely with its performance appraisal process.

3. Stress real time examination and dynamic controlling process

Response speed and foreseeing ability are very important for a system designing, both these abilities are based on a dynamic and real time tracing on the whole operating process. So, we need to build up an integrated IT system which links all the operating factors with investment decision and KPI, and work out a clearly critical path for the whole analysis system.

\subsection{The Layered Structure of This Investment Management System}

Based on the mechanism described above, we built the whole system as a layered structure (Figure 1). From the bottom to the top, they are logic layer, performance layer, and precaution layer respectively. 


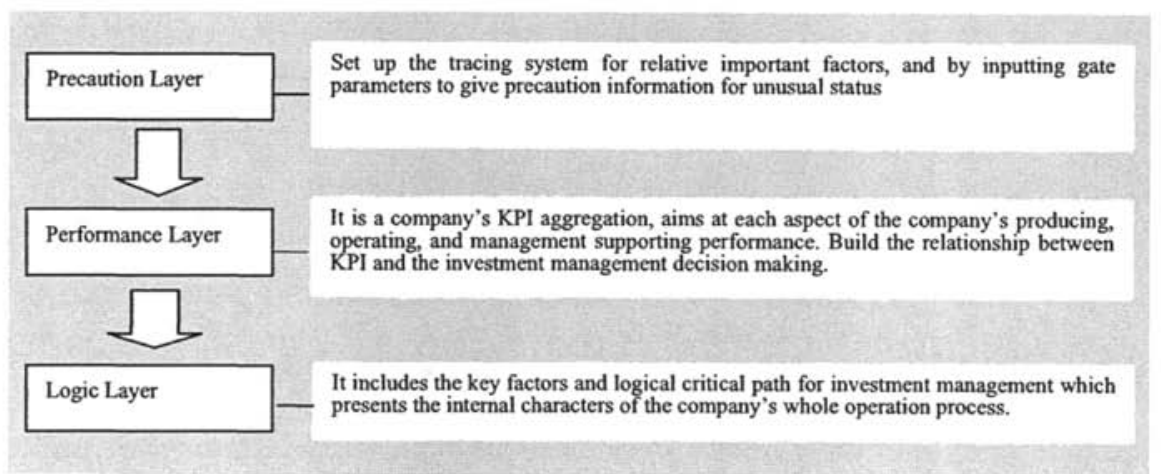

Figure 1. Three-layered Structure of the Investment Management System

\section{SYSTEM DESIGN FOR MOBILE OPERATOR'S INVESTMENT MANAGEMENT}

\subsection{The logic Factor and Critical Path for Mobile Operator's Investment Management}

Tracing mobile operator's operation flow and analyzing its investment path ${ }^{[3]}$, we got figure 2, the critical path and key factors of investment management. In this figure, there have five logic factors: "operating revenue", "total usage", "peak-hour traffic", "carrying capacity", and "investment", which are very important for analyzing the whole route for mobile operators turning its investment into profit. The logic factors and critical path provide a strong theory support for mobile operators to establish their three-layer investment management system.

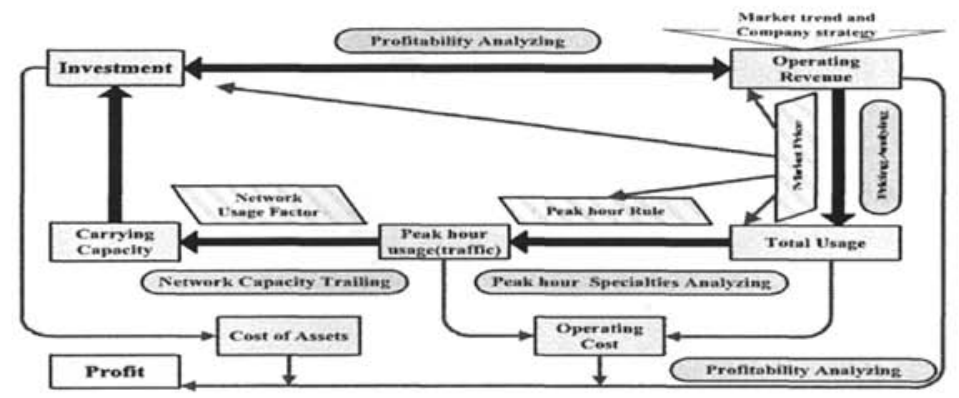

Figure 2. The Critical Path and Key Factors 


\subsection{Design for the Three Layers}

According to the operation characters, the special performance, the internal logic factors and the critical business path, the three layers investment management model of mobile operators is designed as following framework.

\subsubsection{The Logic Layer}

The five key factors mentioned above are important to design the logic layer. With very little change, we make these five factors as revenue, operation volume, customer, price and investment, which shown on Figure 3. The lines linked between each two factors show the basic analysis of the investment decision-making. Through analyzing the relation between these five logic factors, we come up with three groups of relationships among them: (1) the relationship between customer scale, macroenvironment, mobile penetration rate, and service price; (2)the elasticity relationship between operation volume and service price; (3)the relationship between investment, operation volume, and network quality ${ }^{[2]}$. Deeper-seated factors influencing the investment effect can be found by analyzing these three groups of relationships. Obviously, the deeper-seated factors and the logic relationship characterize the mobile operations, which can not be found in other industries.

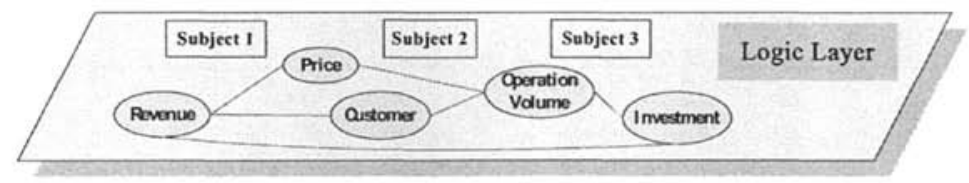

Figure 3. Relationship of Operations Occupying Resources

\subsubsection{The Performance Layer}

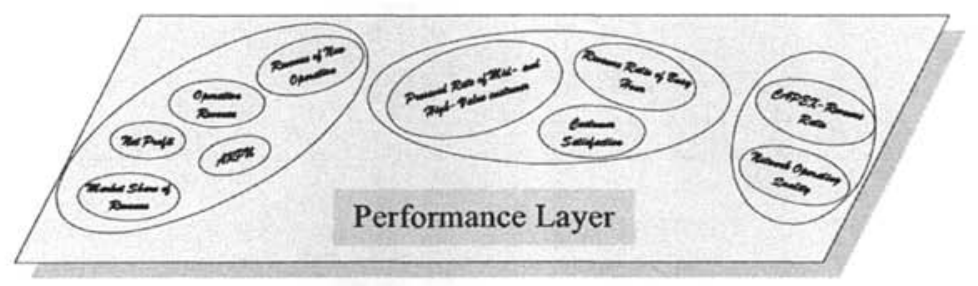

Figure 4. Key Performance Index Analysis

Performance layer is designed to keep this system working along its initial orientation-profitability, it composes of a group of company's key performance index, aims to control the key factors (in the logic layer) keeping their rational relationship. (Figure 4) 


\subsubsection{The Precaution Layer}

The precaution layer is mainly based on enterprise MIS and precaution platform. With huge database and strong analytic function, it gathers various information of enterprise operation, finds out the precautious information timely via precaution platform, and then feed back precautious information to control layer and logic layer to readjust corresponding indexes. So analytical precaution layer of mobile communication operators can be regard as the exterior representation of enterprise operation. From the points of investment management, the usages of analytical precaution layer are incarnated in three aspects: (1)Capacity Precaution(2)Investment Precaution(3)KPI Precaution, which are showed with detail indexed in Figure 5.

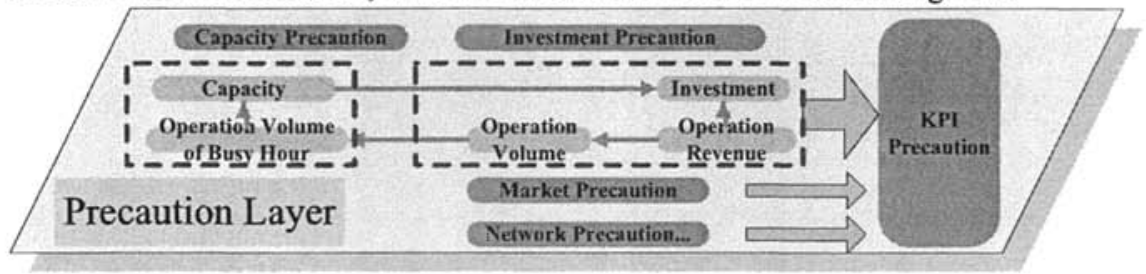

Figure 5. The Precaution Layer

\subsection{The System Integration and Implementation of Mobile Operators}

As the above depiction, integrate the utility of three layer structure, and then form the entire model's integrated framework. As figure 6 shows.

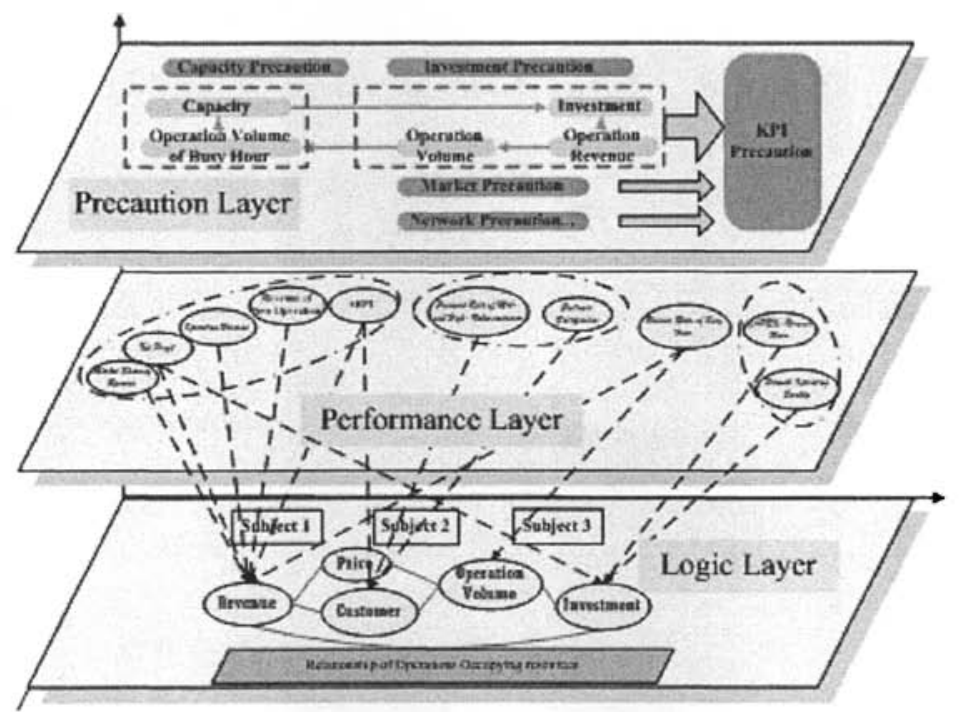

Figure 6. The System Integration 
From the collectivity, carrying out the model needs multi-information from almost all departments of the company, while the validity of model lies on the creating of enterprise integrative information system. So, IT actualization is the prime and essential process of investment management departments make use of MIS to support their operation actions.

This type of investment management system is not a pure financial system, it integrates financial, operation, business and performance all together, the system needs not only a normal company MIS, but also needs to paying equal attention to business process, operation analysis and performance control.

Actually, this system design has already implemented by China mobile's province company (just several for experiment). It is now in using and maintaining stage, and has shown its function and power in investment management

\section{REFERENCES}

1. E. Ann and M. Joe, Telecommunications network total cost of ownership and return on investment modeling, BT Laboratories plc. Volume 21, pp.35-48, (2003).

2. HuaWei Technology Inc., GSM Wireless Network Programming and Optimization (People's Post and Telecommunication Publishing House: 2004).

3. R. Ahuja, T.L. Magnanti, and J. Orlin, Network Flows: Theory, Algorithms, and Applications (Prentice-Hall: Englewood Cliffs, NJ, 1993).

4. W. Yang, Investment Economics (China Finance and Economy Science Publishing House: 1998).

5. Annual Report, China Mobile. http://www.chinamobilehk.com (Accessed June 10, 2007). 